\title{
MEASURING PERSONAL EXPOSURE FROM GSM 900 MHz MOBILE PHONE BASE STATIONS IN AUSTRALIA AND BELGIUM USING A NOVEL PERSONAL DISTRIBUTED EXPOSIMETER
}

Chhavi Raj Bhatt ${ }^{\mathrm{a}, *}$, Arno Thielens ${ }^{\mathrm{b}}$, Mary Redmayne ${ }^{\mathrm{a}}$, Michael J. Abramson ${ }^{\mathrm{a}}$, Baki Billah ${ }^{\mathrm{c}}$, Malcolm R. Sim ${ }^{\mathrm{a}}$, Roel Vermeulen ${ }^{\mathrm{d}, \mathrm{e}, \mathrm{f}}$, Luc Martens ${ }^{\mathrm{b}}$, Wout Joseph $^{\mathrm{b}}$, Geza Benke ${ }^{\mathrm{a}}$

${ }^{a}$ Centre for Population Health Research on Electromagnetic Energy (PRESEE), School of Public Health and Preventive Medicine, Monash University, The Alfred Centre, 99 Commercial Road, Victoria 3004, Melbourne, Australia

${ }^{\mathrm{b}}$ Department of Information Technology, Ghent University/iMinds, Gaston Crommenlaan 8 Box 201, Ghent B-9050, Belgium

c Department of Epidemiology and Preventive Medicine, School of Public Health and Preventive Medicine, Monash University, The Alfred Centre, 99 Commercial Road, Victoria 3004, Melbourne, Australia

${ }^{\mathrm{d}}$ Institute for Risk Assessment Sciences (IRAS), Division Environmental Epidemiology, Utrecht University, Yalelaan 2, 3584 CM Utrecht, The Netherlands

e Julius Centre for Health Sciences and Primary Care, University Medical Center, Utrecht, The Netherlands

${ }^{\mathrm{f}}$ Imperial College, Department of Epidemiology and Public Health, London, United Kingdom

\section{Introduction}

The exposure of humans to radiofrequency-electromagnetic fields (RF-EMFs) is inevitable, due to the omnipresent RF-EMF sources in the modern environment. There are public concerns for potential health effects caused by the use of RF-EMF associated technologies, mobile phones and base stations (Kim et al., 2014; Tjong et al., 2015; Wiedemann et al., 2014). Furthermore, there is currently a strong need for quantification of personal exposures using objective measures for current and future human epidemiological studies (van Deventer et al., 2011).

The personal exposures from far-field RF-EMF sources, including mobile phone base stations, can be evaluated by performing personal measurements in various microenvironments using exposimeters (Dürrenberger et al., 2014; Joseph et al., 2010; Röösli et al., 2010; Urbinello et al., 2014a). However, exposure evaluations with exposimeters still have limitations (Bhatt et al, 2015), which give rise to measurement uncertainties. The uncertainties can reach up to 25$30 \mathrm{~dB}$ (Bolte et al., 2011; Iskra et al., 2011; Neubauer et al., 2010) and include shielding effects of the human body, the multidirectional nature of the incident RF-EMFs, residual calibration, the frequency response of the exposimeter, and the inability to detect signals below the lower detection limits, etc. (Bolte et al., 2011; Gajšek et al., 2015; Iskra et al., 2011 ; Mann, 2010; Neubauer et al., 2010). Measurement uncertainties in personal exposimetry could be reduced by employing on-body calibrated exposimeters (Thielens et al, 2015a).

A personal distributed exposimeter (PDE) with multiple RF-EMF antennas, placed on the body, has been developed recently in order to reduce measurement uncertainties related to shielding effects and directionality of the signal (Thielens et al., 2015a; Thielens et al., 2015b; Thielens 
et al., 2013; Vanveerdeghem et al., 2015). The PDE systems have been tested to measure farfield exposures from the Global System for Mobile communications (GSM) $900 \mathrm{MHz}$ downlink (DL) and Wi-Fi networks (Thielens et al., 2015b; Thielens et al., 2013). In the GSM $900 \mathrm{MHz}$ DL band, the first prototype was developed using three on-body antennas (Thielens et al. 2013), but was not used for actual measurements. A second generation prototype was used for actual exposure measurements (Vanveerdeghem et al. 2015). This system consists of four on-body antennas matched with complementary receiver electronics and is currently the only system available for PDE measurements, which consequently can only consider the GSM $900 \mathrm{MHz}$ DL band at this moment.

Several European studies indicate that mobile phone base stations are a major source of whole body exposure to RF-EMF (Bolte and Eikelboom, 2012; Frei et al., 2009; Gajšek et al., 2015; Joseph et al., 2010; Urbinello et al., 2014b; 2014c; Vermeeren et al., 2013). More specifically, mobile phone base stations are a dominant exposure source to the whole body in urban outdoor environments and on public transport (Joseph et al., 2010; Urbinello et al., 2014a, 2014b).

While much of the information about personal RF-EMF exposure comes from the studies conducted in Europe, similar information from Australia or elsewhere is lacking. There are only limited data on environmental exposure from mobile phone base stations, particularly at locations close to the base stations, that have been reported in Australia (Radio Frequency National Site Archive, 2015; Rowley and Joyner, 2012; Henderson and Bangay, 2006). The utilization of mobile phone technology in Australia has increased substantially during the last two decades. This is similar to what has occurred in Europe, including Belgium, and USA (ACMA paper, 2015; ACMA communications report, 2014). The demands of increased mobile phone signal coverage and signal capacity largely contributed to measured increases in outdoor environmental exposures of $20 \%$ to $57 \%$ in three European cities (including Gent, Belgium) over the course of one year (Urbinello et al., 2014a). Therefore, a comparative study of personal RF-EMF exposure using similar study protocols, involving countries in Europe and elsewhere was needed.

The purposes of this study were: i) to measure personal exposure in the GSM $900 \mathrm{MHz}$ downlink (DL) frequency band with two systems of exposimeters, the PDE (a novel exposimeter) and a pair of ExpoM-RFs, ii) to compare the exposure levels for selected microenvironments in the two countries, and iii) to assess the correlation between the PDE and ExpoM-RFs measurements.

\section{Materials and methods}

\subsection{Study areas}

The study was conducted in urban, suburban, and rural areas in Australia and Belgium (Fig. 1). The measurements were performed by one person (CRB) during $16^{\text {th }}$ April- $8^{\text {th }}$ May and $27^{\text {th }}$ March $-6^{\text {th }}$ April respectively. The study regions in Australia included Victoria, and mainly covered the Greater Melbourne region, and a rural site (Cathedral Range State Park). Similarly, Gent and Mol, the provinces of East Flanders and Antwerp respectively, in the Flemish region 
of Belgium were covered in the study. We considered a region to be urban when the population density was $>400$ people per square kilometre (Joseph et al., 2010).

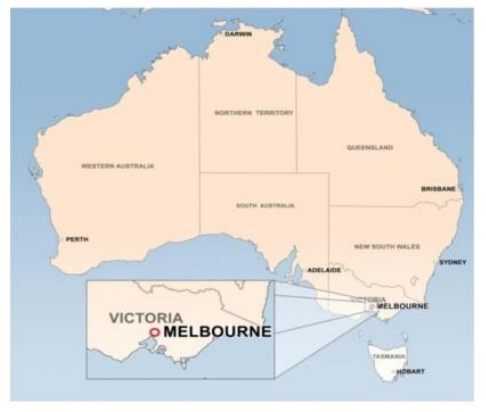

a

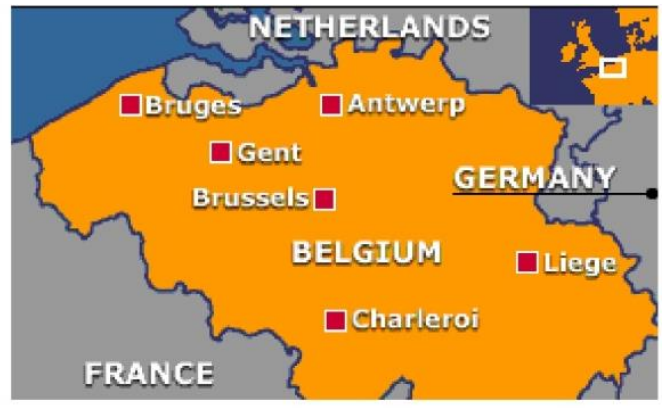

b

Fig. 1. Maps of a) Australia and b) Belgium showing Melbourne and Gent respectively (Sources: https://commons.wikimedia.org, and http://www.bbc.co.uk/, respectively)

A total of 34 matched microenvironments (17 in Australia and 17 in Belgium) were chosen to evaluate personal exposures. A microenvironment is a spatial compartment where a human subject spends time and his/her personal RF-EMF exposure is evaluated for that specific duration (Röösli et al., 2010; Urbinello et al., 2014a, 2014b). The selected microenvironments were similar to those employed in various previous studies (Bolte and Eikelboom, 2012; Frei et al., 2009; Joseph et al., 2010; Röösli et al., 2010; Urbinello et al., 2014a, 2014b). The characteristics of each microenvironment, its spatial characteristics, and the activities undertaken therein by the subject are summarized in Table 1 in Appendix A. The microenvironments were mainly of two types: stationary or mobile. The stationary microenvironments remained fixed while the subject moved around in the microenvironment, whereas the mobile microenvironments moved around during the data collection while the subject generally remained stationary. The mobile microenvironments included bus, train, tram, car and bicycle, whereas stationary microenvironments included the rest, except for subway station/ride, which was a mixed microenvironment.

\subsection{On-body Calibration Procedure}

\subsubsection{The PDE system}

The PDE system was used to perform personal exposure measurements in the GSM 900 downlink (DL) band (925-960 MHz). The PDE system was a collection of three body-worn antennas (see Fig. 2) (2 anterior and 1 posterior) tuned to the mobile phone GSM $900 \mathrm{MHz}$ DL frequency band. The PDE was connected to complementary receiver electronics (Vanveerdeghem et al., 2015) that registered the received power on the antennas. The $E_{\text {inc }}$ (incident electric-field strength) can be determined from the received power on the PDE, using the effective antenna aperture $(A A)$ of the set of antennas (Thielens et al., 2015b, 2015c). Onbody calibration was performed to determine the $A A$. Each PDE antenna attached to a T-shirt, and all antennas' connecting cables were attached to the T-shirt. We assume that this way, there was no or minimum interference of the cables in terms of the PDE's RF response.

\subsubsection{The ExpoM-RFs system}


The ExpoM-RFs measured electric field strengths $\left(E_{b o d y}\right)$ in 16 different frequency bands, including GSM $900 \mathrm{MHz}$ DL. This study only dealt with GSM $900 \mathrm{MHz}$ DL frequency band. ExpoM-RF 64 and ExpoM-RF 40 were used in the calibration process.

\subsubsection{The Calibration procedure}

In this study, we used established on-body calibration procedures (Thielens, 2015a, 2015b, 2015c, 2013; Vanveerdeghem et al., 2015). The calibration took place in an anechoic chamber with a transmitting antenna $\left(T_{X}\right)$ on one side of the chamber and a rotational platform on the other side. The $T_{X}$ emitted a constant output power at $942.5 \mathrm{MHz}$, thus inducing RF-EMFs that were incident on the rotational platform on which the subject could stand.

The subject (a 35-year-old male subject; height $163 \mathrm{~cm}$ and mass $60 \mathrm{~kg}$ ) participated in the onbody calibration in order to conduct subsequent field measurements. The subject did not carry a mobile phone and did not have any metal objects attached to his body during calibration. The calibration procedure is further described in Appendix B.

\subsection{Exposure assessment}

The exposure measurement system consisted of the PDE (prototype) system (Gent University/iMinds, Gent, Belgium) and the two above-mentioned ExpoM-RFs (Fields at Work $\mathrm{GmbH}$, Zürich, Switzerland). The PDE antennas were attached to a T-shirt; 2 front antennas (1 over the right chest, the other on the left abdominal area), and 1 posterior antenna on the central back (Fig. 2). The antennas were wired to a battery and operated with an on/off switch. Each antenna collected the signals simultaneously. Two ExpoM-RFs were attached to the lateral sides of the hip (one each side) using travellers' money belts.

A light jacket was worn by the subject to cover both exposimeter systems while carrying out the field measurements (Fig. 2). The subject did not have any metal objects attached to his body during the data collection. A diary was maintained in order to record information on activities undertaken during data collection and descriptions of the microenvironments. All measurements were performed during the daytime $(9: 45 \mathrm{am}-6: 00 \mathrm{pm})$ or evening hours $(6: 00$ $\mathrm{pm}-11: 00 \mathrm{pm})$ on weekdays, except the measurements of residential outdoor and residential indoor (rural/suburban) in Belgium, which were performed during the weekends (2:30-2:45 pm and 11:00-11:15 pm respectively). The RF-EMF measurements during the daytime and evening on weekdays were expected to provide the highest values of exposure (Joseph et al., 2010).

Each measurement duration was 15 minutes per microenvironment. Urbinello et al. (2014a, 2014b) have employed similar measurement duration to monitor personal exposures. A smart phone was used to monitor measurement time during the measurements; it was in flight mode to prevent it from transmitting and receiving signals during data collection. The measurement interval for the PDE and the ExpoM-RFs were chosen to be 1 and 3 seconds, respectively.

On average, the PDE collected a total of 900 samples on each antenna per microenvironment measurement session. Similarly, each ExpoM-RF collected 300 data samples per measurement. Most of the microenvironment measurements were performed twice (Table 1 in Appendix A) to check exposure variability. 
In Australia, the measurements in three microenvironments involved three and two antennas' data at the time of the first and second measurements, respectively; whereas a microenvironment involved measurement with two antennas (Table 2). Similarly, a microenvironment in Belgium involved two antennas' data during both measurements, and the other microenvironment involved three and two antennas' data during the first and the second measurements respectively (Table 2). The detection range of the PDE (with on-body calibration) was $5.9 \mathrm{mV} / \mathrm{m}-59 \mathrm{~V} / \mathrm{m}$. The detection range for the ExpoM-RFs for GSM $900 \mathrm{MHz} \mathrm{DL}$ reported in the datasheet of the devices (without on-body calibration) was $5 \mathrm{mV} / \mathrm{m}-5 \mathrm{~V} / \mathrm{m}$. After an on-body calibration, the detection range of the ExpoM-RFs was estimated at $10 \mathrm{mV} / \mathrm{m}-10 \mathrm{~V} / \mathrm{m}$. Both devices measured the root mean square electric field strengths $\left(E_{r m s}\right)$ in $\mathrm{V} / \mathrm{m}$. The measured data of the PDE were then processed using the corresponding $A A$ and detection limit of the relevant pair of antennas. Similarly, geometric mean of the on-body calibration factors of the ExpoM-RFs was used to process the measured ExpoM-RFs data, see section 3.1.

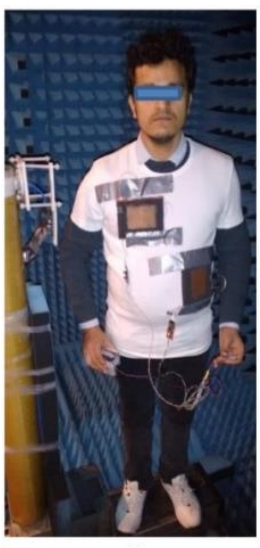

a

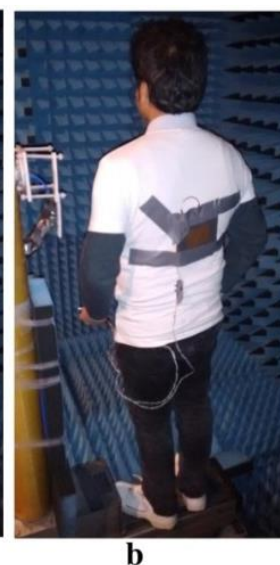

b

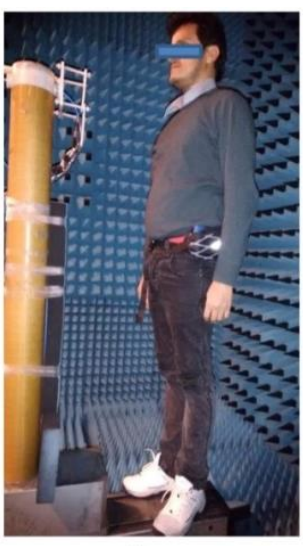

c

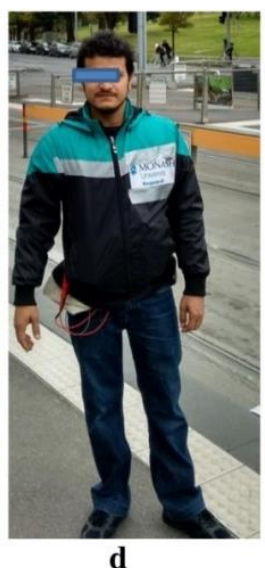

d

Fig.2: The human subject performing i) an on-body calibration of the PDE (figures a \& b), and ii) ExpoM-RFs (figure c), in Gent, Belgium, ii) exposure measurement at a site in Melbourne, Australia (figure d)

\subsection{Data processing and Statistical analysis}

The PDE data output provided the incident electric fields for a geometric mean of the given combination of antennas. Geometric means of the electric field signals obtained with two ExpoM-RFs were computed over time within the selected sample intervals using the formula; Geometric mean $=\left(E_{\text {ExpoM-RF40 }} \times E_{\text {ExpoM-RF64 }}\right)^{1 / 2}$. The normality of the geometric mean data of the PDE and ExpoM-RFs for each microenvironment and each measurement session (i.e. measurement 1 and measurement 2) were examined by Shapiro-Wilk tests of both untransformed and log-transformed data. In addition, visual inspection of histograms and the normal Q-Q plots was also performed. Measurements 1 and 2 represented the first and the second (repeated) measurements, respectively.

Medians ( $25^{\text {th }}$ and $75^{\text {th }}$ percentiles) and ranges (minimum, maximum) of the electric field strengths were calculated from the geometric means of the PDE and ExpoM-RFs data obtained 
from the combination of antennas and two ExpoM-RFs, respectively. The values measured by the individual antennas of the PDE and individual ExpoM-RF were not considered in this study. The exposures measured with the ExpoM-RFs were only used while evaluating the agreement between two devices' measurements.

Personal exposure levels were described by summary statistics of the electric field strengths measured with the PDE. The personal exposures across similar microenvironments in Australia $(n=14)$ and Belgium $(n=14)$ were compared. Six microenvironments were excluded from the comparison: residential indoor (urban), subway station/ride (urban), mountain/forest (rural) in Australia ( $\mathrm{n}=3$ ), and bicycle (rural/suburban), residential indoor (rural/suburban) and car (rural/suburban) in Belgium $(n=3)$. These were excluded because each comparable corresponding microenvironment in the other country was not assessed.

The Shapiro-Wilk test and evaluation of histograms and normal Q-Q plots indicated that none of the microenvironments followed a normal or lognormal distribution of the personal exposure electric field levels. Therefore Wilcoxon rank sum tests were performed on the exposure data of the compared microenvironments in order to examine whether the exposures across those microenvironments in Australia and Belgium were different. The assessment of exposure variability during the first and second measurements was done by performing Wilcoxon rank sum tests. Thirteen microenvironments in Australia and 6 microenvironments in Belgium, which had repeated measurements, were evaluated.

The correlations between the PDE and ExpoM-RFs measurements were evaluated on the median exposure data of 34 microenvironments (17 in each country). The evaluation was performed also for 21 stationary (11 in Australia and 10 in Belgium) and 13 mobile microenvironments (6 in Australia and 7 in Belgium).

For all statistical tests, the $\mathrm{p}<0.05$ (two sided) was considered as statistically significant. All data analysis was carried out using MATLAB R2015a (The MathWorks Inc, Natick, Massachusetts, USA) or STATA ver13.1 (StataCorp, College Station, TX, USA).

\section{Results}

\subsection{Calibration of the exposimeter systems}

The median antenna aperture of the PDE worn on the body, calculated over a 100 repetitions of the same processing, was found to be $1.05 \mathrm{~cm}^{2}$ (inter quartile range $1.04 \mathrm{~cm}^{2}-1.06 \mathrm{~cm}^{2}$ ). The value of the prediction interval $\left(P I_{50}\right)$ for antenna aperture of the PDE was $3.3 \mathrm{~dB}$.

The median responses of the ExpoM-RFs worn on the body and the geometric average of both ExpoM-RFs, calculated over 100 repetitions of the same processing, were found to be 0.502 (inter quartile range $0.502-0.503$ ) [ExpoM-RF 40], 0.533 (inter quartile range $0.532-0.534$ ) [ExpoM-RF 64], and 0.507 (inter quartile range 0.507 - 0.508) [geometric average of two ExpoM-RFs]. 
The values of $\mathrm{PI}_{50}$ on the response of the ExpoM-RFs were $5.9 \mathrm{~dB}$ (ExpoM-RF 40), $3.6 \mathrm{~dB}$ (ExpoM-RF 64) and $4.2 \mathrm{~dB}$ for the geometric average of the two ExpoM-RFs. 


\subsection{Descriptive statistics}

The $E_{r m s}$ values of all the measured signals were found to be above the lower measurable threshold of the PDE. Table 2 below summarizes the personal exposure levels across different microenvironments in Australia and Belgium.

Table 2. Personal exposures $\left(\mathrm{E}_{\mathrm{rms}}\right.$ in $\left.\mathrm{V} / \mathrm{m}\right)$ across various microenvironments in Australia and Belgium [median $\left(25^{\text {th }}, 75^{\text {th }}\right.$ percentiles) and range $(\mathrm{min}$, max $)$ ]

\begin{tabular}{|c|c|c|c|c|}
\hline \multirow[t]{2}{*}{ Microenvironments } & \multicolumn{2}{|c|}{ Australia } & \multicolumn{2}{|c|}{ Belgium } \\
\hline & Median $\left(25^{\text {th }}, 75^{\text {th }}\right.$ percentiles $)$ & $\begin{array}{c}\text { Range } \\
(\min , \max )\end{array}$ & Median $\left(25^{\text {th }}, 75^{\text {th }}\right.$ percentiles $)$ & $\begin{array}{l}\text { Range } \\
(\min , \max )\end{array}$ \\
\hline Residential outdoor (urban) & $0.044(0.029,0.075)^{2, \mathrm{a}}$ & $0.017,0.197$ & $0.139(0.094,0.197)^{1, \mathrm{a}}$ & $0.022,0.494$ \\
\hline Residential indoor (urban) & $0.019(0.016,0.024)^{2, a}$ & $0.008,0.047$ & - & - \\
\hline Office indoor (urban) & $0.018(0.016,0.021)^{2, \mathrm{a}}$ & $0.010,0.046$ & $0.032(0.027,0.039)^{2, \mathrm{a}}$ & $0.010,0.091$ \\
\hline Park (urban) & $0.051(0.029,0.065)^{2, \mathrm{a}}$ & $0.019,0.156$ & $0.124(0.091,0.162)^{2, \mathrm{a}}$ & $0.034,0.458$ \\
\hline City centre & $0.248(0.102,0.324)^{2, a b}$ & $0.006,0.647$ & $0.156(0.115,0.182)^{1, \mathrm{a}}$ & $0.057,0.278$ \\
\hline Library (urban) & $0.049(0.036,0.062)^{2, \mathrm{a}}$ & $0.014,0.124$ & $0.110(0.088,0.145)^{1, \mathrm{a}}$ & $0.038,0.278$ \\
\hline Shopping centre (urban) & $0.021(0.019,0.025)^{1, \mathrm{a}}$ & $0.015,0.115$ & $0.028(0.025,0.034)^{1, \mathrm{a}}$ & $0.015,0.204$ \\
\hline Railway station (urban) & $0.105(0.074,0.117)^{2, a b}$ & $0.042,0.331$ & $0.034(0.023,0.169)^{1, \mathrm{a}}$ & $0.015,0.534$ \\
\hline Tram station (urban) & $0.038(0.030,0.060)^{2, a}$ & $0.007,0.075$ & $0.238(0.204,0.267)^{1, \mathrm{a}}$ & $0.139,0.622$ \\
\hline Bicycle (urban) & $0.017(0.007,0.041)^{2, \mathrm{ab}}$ & $0.007,0.221$ & $0.238(0.169,0.300)^{1, \mathrm{a}}$ & $0.053,0.784$ \\
\hline Bicycle (rural/suburban) & - & - & $0.012(0.010,0.013)^{1, \mathrm{a}}$ & $0.009,0.035$ \\
\hline Bus (urban) & $0.124(0.065,0.213)^{2, \mathrm{a}}$ & $0.027,0.555$ & $0.028(0.019,0.049)^{2, \mathrm{~b}}$ & $0.007,0.556$ \\
\hline Car (urban/suburban) & $0.006(0.006,0.006)^{1, \mathrm{a}}$ & $0.006,0.049$ & $0.041(0.023,0.065)^{2, a b}$ & $0.007,0.387$ \\
\hline Car (rural/suburban) & - & - & $0.016(0.013,0.020)^{1, \mathrm{a}}$ & $0.009,0.070$ \\
\hline Tram (urban) & $0.041(0.035,0.058)^{2, \mathrm{a}}$ & $0.006,0.197$ & $0.055(0.029,0.124)^{1, \mathrm{a}}$ & $0.017,0.441$ \\
\hline Train & $0.055(0.030,0.115)^{2, a b}$ & $0.011,0.534$ & $0.020(0.017,0.027)^{1, \mathrm{a}}$ & $0.011,0.084$ \\
\hline Subway station/ride (urban) & $0.031(0.027,0.039)^{1, \mathrm{a}}$ & $0.015,0.312$ & - & - \\
\hline Residential outdoor (rural/suburban) & $0.006(0.006,0.006)^{2, a}$ & $0.006,0.051$ & $0.014(0.011,0.044)^{2, \mathrm{a}}$ & $0.010,0.088$ \\
\hline Residential indoor (rural/suburban) & - & - & $0.017(0.016,0.019)^{2, \mathrm{a}}$ & $0.013,0.031$ \\
\hline Mountain/forest (rural) & $0.057(0.049,0.061)^{1, \mathrm{~b}}$ & $0.012,0.068$ & - & - \\
\hline
\end{tabular}

1 = single measurement, $2=$ repeated measurement; $a=3$-antennas' data, $b=2$ antennas' data; $a b=3$ antennas' data in one measurement and 2 antennas' data in the other measurement 
In Australia, the five highest median exposure levels (from mobile phone base stations) measured were: city centre $(0.248 \mathrm{~V} / \mathrm{m})$, bus $(0.124 \mathrm{~V} / \mathrm{m})$, railway station $(0.105 \mathrm{~V} / \mathrm{m})$, mountain/forest (rural) $(0.057 \mathrm{~V} / \mathrm{m})$, and train $(0.055 \mathrm{~V} / \mathrm{m})$. Similarly, the five lowest median exposures measured were: car (urban/suburban) $(0.006 \mathrm{~V} / \mathrm{m})$, residential outdoor (rural/suburban) $(0.006 \mathrm{~V} / \mathrm{m})$, bicycle (urban) $(0.017 \mathrm{~V} / \mathrm{m})$, office indoor (urban) $(0.018 \mathrm{~V} / \mathrm{m})$, and residential indoor (urban) $(0.019 \mathrm{~V} / \mathrm{m})$.

In Belgium, the five highest median exposures measured were: bicycle (urban) $(0.238 \mathrm{~V} / \mathrm{m})$, tram station $(0.238 \mathrm{~V} / \mathrm{m})$, city centre $(0.156 \mathrm{~V} / \mathrm{m})$, residential outdoor (urban) $(0.139 \mathrm{~V} / \mathrm{m})$, and park $(0.124 \mathrm{~V} / \mathrm{m})$. Similarly, the five lowest exposure levels measured were: bicycle (rural/suburban) $(0.012 \mathrm{~V} / \mathrm{m})$, residential outdoor (rural/suburban) $(0.014 \mathrm{~V} / \mathrm{m})$, car (rural/suburban) $(0.016 \mathrm{~V} / \mathrm{m})$, residential indoor (rural/suburban) $(0.017 \mathrm{~V} / \mathrm{m})$, and train $(0.020$ $\mathrm{V} / \mathrm{m})$.

\subsection{Comparison of exposure levels in Australia and Belgium}

We found that personal exposures across most of the microenvironments in Australia were significantly lower $(\mathrm{p}<0.05)$ than the exposure across the microenvironments in Belgium. However, there were a few microenvironments where the exposure in Australia was higher $(\mathrm{p}<0.05)$ than the corresponding exposure in Belgium. For instance, the city centre results in Melbourne were significantly higher $(\mathrm{p}<0.001)$ than the exposure level at the city centre of Gent, as were exposures in the Melbourne train and during a bus ride, than those in Gent.

\subsection{Evaluation of the variability of exposures}

Table 3 shows the results of the Wilcoxon rank sum tests that was were performed to evaluate if the repeated measurements provided similar exposure levels. The analysis showed that the majority of the microenvironments (13 of 19) provided significantly different median exposure levels at the measurements 1 and 2, suggesting that both measurements had highly varied exposures. The microenvironments demonstrating similar exposures at both measurements were: residential indoor (urban), office indoor (urban), library (urban), and residential outdoor (rural/suburban) [Australia], and office indoor (urban) and park (urban) [Belgium].

Spatial matching of the repeated stationary microenvironmental measurements was ensured by walking across the same area and towards the same direction. In case of the repeated mobile microenvironments, the matching was accomplished by sitting/standing at the same spot/around the same positions with respect to window and carriage dimension. All mobile microenvironment measurements, except for car (urban) and bus (urban) in Belgium, were performed exactly in the same routes. The temporal matching, for most of the measurements, was ensured by performing the measurements $\left(1^{\text {st }}\right.$ and $\left.2^{\text {nd }}\right)$ around similar timings of the day such as morning, evening or night. 
Table 3. Evaluation of the variability in personal exposure measurements [medians at $M_{1}$ (measurement 1 ) and $M_{2}$ (measurement 2) in $V / m$ ]

\begin{tabular}{|c|c|c|c|c|}
\hline Microenvironments & Countries & Median $\left(25^{\text {th }},{75^{\text {th }}}\right.$ percentiles $)$ at $M_{1}$ & Median $\left(25^{\text {th }},{75^{\text {th }}}\right.$ percentiles $)$ at $\mathrm{M}_{2}$ & *p values \\
\hline Residential outdoor (urban) & Australia $^{a}$ & $0.055(0.034,0.098)$ & $0.041(0.026,0.062)$ & $<0.001$ \\
\hline Residential indoor (urban) & Australia $^{\text {a }}$ & $0.017(0.014,0.031)$ & $0.019(0.016,0.023)$ & 0.17 \\
\hline Office indoor (urban) & Australia $^{a}$ & $0.017(0.016,0.019)$ & $0.016(0.015,0.023)$ & 0.46 \\
\hline Office indoor (urban) & Belgium $^{\text {a }}$ & $0.033(0.028,0.044)$ & $0.034(0.029,0.041)$ & 0.29 \\
\hline Park (urban) & Australia $^{a}$ & $0.046(0.030,0.055)$ & $0.055(0.028,0.070)$ & $<0.001$ \\
\hline Park (urban) & Belgium $^{\text {a }}$ & $0.106(0.078,0.156)$ & $0.106(0.084,0.134)$ & 0.91 \\
\hline City centre & Australia ${ }^{a b}$ & $0.324(0.289,0.386)$ & $0.081(0.015,0.162)$ & $<0.001$ \\
\hline Library (urban) & Australia $^{\text {a }}$ & $0.055(0.047,0.062)$ & $0.055(0.049,0.065)$ & 0.17 \\
\hline Railway station (urban) & Australia ${ }^{a b}$ & $0.117(0.105,0.132)$ & $0.081(0.057,0.106)$ & $<0.001$ \\
\hline Tram station (urban) & Australia $^{\mathrm{a}}$ & $0.031(0.028,0.035)$ & $0.060(0.053,0.062)$ & $<0.001$ \\
\hline Bicycle (urban) & Australia ${ }^{a b}$ & $0.035(0.020,0.057)$ & $0.007(0.007,0.007)$ & $<0.001$ \\
\hline Bus (urban) & Australia ${ }^{a}$ & $0.115(0.053,0.204)$ & $0.134(0.069,0.238)$ & $<0.001$ \\
\hline Bus (urban) & Belgium $^{b}$ & $0.046(0.024,0.069)$ & $0.021(0.018,0.030)$ & $<0.001$ \\
\hline Car (urban) & Belgium ${ }^{a b}$ & $0.057(0.044,0.088)$ & $0.022(0.014,0.038)$ & $<0.001$ \\
\hline Tram (urban) & Australia $^{a}$ & $0.041(0.036,0.049)$ & $0.036(0.029,0.053)$ & $<0.001$ \\
\hline Train & Australia ab & $0.058(0.024,0.137)$ & $0.057(0.033,0.102)$ & 0.024 \\
\hline Residential indoor (rural/suburban) & Belgium $^{a}$ & $0.019(0.017,0.021)$ & $0.015(0.015,0.016)$ & $<0.001$ \\
\hline Residential outdoor (rural/suburban) & Australia ${ }^{a}$ & $0.006(0.005,0.006)$ & $0.006(0.005,0.006)$ & 0.22 \\
\hline Residential outdoor (rural/suburban) & Belgium $^{\text {a }}$ & $0.047(0.037,0.057)$ & $0.011(0.011,0.012)$ & $<0.001$ \\
\hline
\end{tabular}

$\mathrm{a}=3$-antennas' data, $\mathrm{b}=2$ antennas' data; $\mathrm{b}=2$ antennas' data; $\mathrm{ab}=3$ antennas' data in one measurement and 2 antennas' data in the other measurement,

* $\mathrm{p}$ values $<0.05$ statistically significant different exposure levels 


\subsection{Correlation between the PDE and the ExpoM-RFs measurements}

The overall Spearman correlation coefficient for all microenvironments was 0.63 ( $\mathrm{p}<0.001)$. Similarly, the correlation coefficients for stationary and mobile microenvironments were 0.71 $(\mathrm{p}<0.001)$ and $0.28(\mathrm{p}=0.24)$, respectively.

\section{Discussion}

We have reported the personal far-field RF-EMF exposures from the GSM $900 \mathrm{MHz}$ downlink frequency band across the various microenvironments in Australia and Belgium, using a novel on-body calibrated PDE system. Monitoring of exposures across various microenvironments, including those investigated in our work, is one of the approaches to assess human exposure (Dürrenberger et al., 2014; Joseph et al., 2010; Röösli et al., 2010; Urbinello et al., 2014a).

\subsection{Exposure characteristics in Australia and Belgium}

The personal exposure levels experienced across various microenvironments varied according to the location and type of microenvironment. Previous studies also found variation in exposure across various microenvironments (Bolte and Eikelboom, 2012; Frei et al., 2009; Joseph et al., 2010; Urbinello et al., 2014a). Spatial factors, such as the location of the measurement sites (urban, suburban, rural, outdoor, indoor etc.), distance to nearby base stations; temporal factors (e.g. day, time and season when the measurements were performed), and existing mobile phone traffic are likely to impact the levels of far-field personal exposures (Bolte and Eikelboom, 2012; Joseph and Verloock, 2010; Manassas et al., 2012; Urbinello et al., 2014b; Vermeeren et al., 2013).

The exposure levels found in our study were well below the reference levels for the general public as provided in the guidelines of the International Commission on Non-Ionizing Radiation Protection (ICNIRP, 1998) and the Australian Radiation Protection and Nuclear Safety Agency (Radiation Protection Standard, 2002). The mean exposures in Australia measured were in the range of $0.02-3.65 \%$ of the reference level, whereas those in Belgium were in the range of 0.03-2.73\% of the reference level. The reference level for GSM $900 \mathrm{MHz}$ DL specified by the guidelines is equivalent to $42 \mathrm{~V} / \mathrm{m}[$ Erms $=1.37 \times(f) 0.5 \mathrm{~V} / \mathrm{m}]$ at 942.5 MHz. However, it should be borne in mind that these guidelines are designed to protect against immediate RF-EMF effects from elevated tissue temperatures from absorbed energy during exposure and do not cover possible health or bio-effects related to long-term low-level exposures.

The city centre of Melbourne, which exhibited the highest exposure, is a central business district with strong cell phone network coverage (OpenSignal, 2015; Radio Frequency National Site Archive, 2015). Furthermore, other high exposure microenvironments in Australia were either characterised with densely sited mobile phone towers [e.g. railway station, residential outdoor (urban)] or use of public transport (e.g. bus and train). Except for bicycle (urban), the lowest exposure contributing microenvironments in Australia were either located in rural and suburban regions of Melbourne [car (urban/suburban), residential outdoor (rural/suburban)], or were indoor microenvironments [office indoor and residential indoor (urban)]. The rural and suburban microenvironments in Melbourne were located about $20 \mathrm{~km}$ northeast of Melbourne's city centre with relatively fewer mobile phone towers (OpenSignal, 2015; Radio Frequency National Site Archive, 2015) and lower population density. 
Of all microenvironments in Belgium, the tram station and bicycle provided the highest exposures, mainly due to denser base stations. During the measurements, two mobile phone towers were sited near the tram station and three mobile phone towers were situated in the subject's line-of-sight while performing the bicycle measurements. The other high exposure microenvironments, city centre, residential outdoor and park were characterised by higher mobile phone tower density and stronger network signal strength (Antenna Site Register, 2015; OpenSignal, 2015). As visualised on online databases of mobile phone base stations and signal strength, the density of base stations and signal strengths across these areas is relatively high compared to that in rural and suburban regions of Belgium (Mol). The microenvironments located in the rural and suburban regions of Mol (e.g. bicycle, residential outdoor, residential indoor, and car] provided the lowest exposure. These regions only have a few base stations, low signal strength and low population density.

In general, the exposures measured across most microenvironments in Australia were much lower than those measured across similar microenvironments in Belgium. Higher population density and building characteristics (densely sited and fewer tall buildings) may have attributed to the higher observed exposures across most of the microenvironments in Belgium (Gent) compared to those observed across the microenvironments in Australia (Melbourne). Interestingly, the city centre and train in Australia characterised higher exposures compared to those of the city centre of Gent and the train in Belgium. This is due to the fact that Melbourne city centre has many densely sited base stations and high rise buildings compared to Gent. In the case of the train in Melbourne, a train travelled within the urban regions with many people travelling on board. Whereas the train from Gent to Antwerp mostly travelled through suburban and rural regions, where the mobile phone network was expected to be weaker. Furthermore, trains in Belgium have windows with metallic coatings on them, which make them very good Faraday cages, subsequently providing low downlink exposure levels. These reasons probably explained why the train in Melbourne provided higher downlink exposure than in Gent. The measurements in Belgium and Australia were performed during Spring and Autumn respectively. Furthermore, RF-EMF is also absorbed by the leaves of trees, which would vary according to the amount of foliage present according to different seasons of the year. Mobile phone base stations vary their broadcasting power to provide optimum signal coverage (Bolte and Eikelboom, 2012). Finally, the two countries also have some differences in terms of their natural environments and physical infrastructures, which may influence the mobile phone network in specific areas. The mobile telecommunication systems have been evolving from $2 \mathrm{G}$ to $3 \mathrm{G}$ worldwide, including in Australia and Belgium (International Telecommunication Union, 2010). The difference in mobile phone base station exposure between these two countries can also be linked to such evolution and is therefore unlikely to be stable in time.

It was also observed that the personal exposures in urban microenvironments were much higher than those in rural and suburban microenvironments in both Australia and Belgium. Furthermore, the exposure levels across indoor microenvironments were much lower than those across the outdoor microenvironments. It is well known that microenvironments in an urban area generally provide higher GSM DL exposure compared to those located in rural or suburban areas (Bolte and Eikelboom, 2012; Joseph et al., 2010; Urbinello et al., 2014a, Vermeen et al., 2013). Likewise, indoor microenvironments provide lower GSM DL exposure than outdoor microenvironments (Bolte and Eikelboom, 2012; Joseph et al., 2010; Urbinello et al., 2014a). 
The exposure levels found in our study can be compared to those reported by previous studies conducted in Belgium and other parts of Europe (e. g. Joseph et al., 2010; Urbinello et al., 2014a, 2014b). Joseph et al., (2010) examined the combined downlink (GSM 900, GSM 1800 and UMTS 2100) personal exposure across similar microenvironments in Belgium, Switzerland, Slovenia, Hungary, and the Netherlands, and reported mean exposures for similar microenvironments such as urban outdoor, office, train, car/bus, urban residential (indoor). Similarly, Urbinello et al. (2014a, 2014b) also evaluated the combined downlink personal exposure across similar microenvironments in Gent and Brussels (Belgium) and Basel (Switzerland) - residential outdoor (central urban), residential outdoor, city centre, suburban outdoor, train, tram/metro, bus, train station and shopping centre. In general, the mean exposures reported in these studies were slightly lower than those reported in our study (mean exposure values not shown in table 2). We need to be cautious comparing the exposure reported in our study with those reported in previous studies. The main reasons are: i) we employed an on-body calibrated exposimeter with 3 antennas while those studies used a free space calibrated, single antenna exposimeter (EME Spy) with different measurement intervals, ii) we have only measured GSM $900 \mathrm{MHz}$ DL whereas these studies measured combined downlink signals of three frequency bands. Furthermore, the spatial and temporal characteristics of measurements and measured microenvironments applicable to these studies may have also differed.

Our study demonstrated that GSM $900 \mathrm{MHz}$ DL signals may be highly variable in the same microenvironment on different days. Urbinello et al., (2014c) showed that the environmental exposure levels of mobile phone DL signals across the same areas demonstrated variability in exposure levels. In general, diurnal variation in mobile phone signals in human environments is possible according to spatio-temporal factors (Manassas et al., 2012; Vermeeren et al., 2013; Urbinello et al., 2014c).

The Spearman correlations between the exposure measured with the PDE and that measured with the ExpoM-RFs for all microenvironments were high. The correlation between the exposure measured with the PDE and that measured with the ExpoM-RFs seemed to be higher in the case of the Belgian microenvironments compared to the Australian microenvironments (results not shown). This is likely because overall exposure levels in Australia were lower than in Belgium. The correlation was much stronger in stationary microenvironments compared than mobile microenvironments (transportation). This may be due to the fact that the subject was essentially stationary (seated or standing only) in the mobile microenvironments. On the other hand, the subject moved across the stationary microenvironments, allowing some averaging out of body shielding.

\subsection{Calibration of the exposimeters}

A median antenna aperture of the PDE worn on the body was $1.05 \mathrm{~cm}^{2}$. This is lower than the values found in Vanveerdeghem et al. (2015) $\left(6.6 \mathrm{~cm}^{2}\right)$ and Thielens et al. (2015c) $\left(6.1 \mathrm{~cm}^{2}\right)$. We attribute this to the different on-body setup ( 3 antennas instead of four) and the different assumption on the incident polarizations. In this paper, no assumptions were made on the incident polarization, since the PDE was to be used in different microenvironments that all have their own characteristic polarization distribution. Whereas Vanveerdeghem et al. (2015) $\left(6.6 \mathrm{~cm}^{2}\right)$ and Thielens et al. (2015c) used the PDE only in an urban environment and consequently a-priori assumptions could be made on incident polarizations. However, the antenna aperture is in the same order of magnitude and realistic for this type of on-body antenna (Thielens et al., 2015c; Vanveerdeghem et al., 2015). The corresponding value of the $P I_{50}$ for antenna aperture of the PDE was $3.3 \mathrm{~dB}$, which is much lower than measured in our study for the individual antennas (i.e.13.6 dB, $6.5 \mathrm{~dB}$, and $6.1 \mathrm{~dB}$ ). The value was also lower than that 
reported for single antennas in the same frequency band (Thielens et al., 2013, 2015c; Vanveerdeghem et al. 2015). This indicates that averaging over multiple antennas on the body reduces the variation on the antenna aperture. In Thielens et al. (2013), $P I_{50}$ value of $4.5 \mathrm{~dB}$ was measured for a different set-up with three antennas on the body, which indicates that the on-body setup used in this study is closer to an isotropic antenna. An isotropic antenna allows measurements with the same intensity of signals to be performed irrespective of the measurement direction. In Thielens et al. (2015c) a setup with four antennas on the body yielded a slightly lower $P I_{50}$ of $3.1 \mathrm{~dB}$, which was to be expected since more antennas on the body leads to lower $P I_{50}$ values.

The responses of the ExpoM-RFs indicated that the devices underestimated the incident electric field strengths by a factor of approximately 2 . The $P I_{50}$ of the geometric average of the two ExpoM-RFs was found to be lower than that of one of the individual ExpoM-RFs (i.e. ExpoMRF 40). The responses and PI50 values of the ExpoM-RFs can be compared to those observed in previous studies. Bolte et al. (2011) measured responses in the GSM $900 \mathrm{MHz}$ DL band between $-20 \mathrm{~dB}$ and $+3 \mathrm{~dB}$ were on the body, with median responses below $0 \mathrm{~dB}$ (a factor of 1), which agrees with our results. Thielens et al. (2015a) reported values between $-10 \mathrm{~dB}$ and $+5 \mathrm{~dB}$ in the same frequency band, with a median underestimation, which is in line with our calibration results. The $P I_{50}$ value observed in our study was lower than what was found for a single exposimeter in other studies in the same frequency band of GSM $900 \mathrm{MHz}$ DL. In Bolte et al. (2011), a single exposimeter (EME Spy 121) was worn on the right hip of a subject rotated over $360^{\circ}$ under exposure in the same frequency band. $P I_{50}$ values of $6.5 \mathrm{~dB}$ and $15.5 \mathrm{~dB}$ were measured for two orthogonal polarizations. Thielens et al. (2015a), measured $P I_{50}$ values of 8.3 $\mathrm{dB}$ and $9.6 \mathrm{~dB}$ for an exposimeter (EME Spy 140) placed on the right and left hips, respectively. In the same study, a value of $4.6 \mathrm{~dB}$ was found for an average over the two exposimeters worn on both hips, which corresponds very well with the $4.2 \mathrm{~dB}$ observed in our study.

\subsection{Strengths, limitations and implications}

To our knowledge, this is the first microenvironmental exposure study to evaluate RF-EMF exposures with the use of a novel, on-body calibrated system of exposimeter, with multiple antennas. The study also provides a basis for a direct valid comparison of exposures across the microenvironments in Australia and Belgium with different geophysical, environment and weather conditions. Furthermore, this study evaluates the correlation between the PDE and the ExpoM-RFs measurements while measuring GSM $900 \mathrm{MHz}$ DL personal exposure.

All the received RF-EMF signals collected in this study were above the lower measurable threshold of the PDE. This is a major strength of this study as it meant there was no issue related to measurements below the lower detection threshold, which has been noted as a major challenge in exposure assessment (Bolte and Eikelboom, 2012; Frei et al., 2009; Gajsek et al., 2013; Joseph et al., 2010; Juhász et al., 2011; Urbinello et al., 2014b). Our study employed ExpoM-RFs, which demonstrated no problem with the issue of detection threshold. Another major strength of our study is that this approach minimised the measurement uncertainties related to body shielding as the PDE consisted of three antennas, which would be expected to provide a much more accurate representation of true personal exposure with fewer measurement uncertainties. 
The limitations associated with the study were: i) only GSM $900 \mathrm{MHz}$ DL frequency was considered, ii) the personal exposure was measured only for few selected microenvironments, which means the exposures could not be generalised to other microenvironments, ii) not all measurements were repeated and data were not always obtained with all three antennas of the PDE, iii) each measurement duration was only 15 minutes

The feasibility of the PDE system for assessing RF-EMF exposures in future epidemiological studies was demonstrated. Therefore, this study contributes towards an improved exposure assessment approach for RF-EMF epidemiological studies. However the use of an on-body calibrated exposimeter in epidemiological research may not be the most pragmatic approach, since an on-body calibration of the human subject is time intensive and costly work, which is not practicable for large number of subjects in epidemiological studies. In addition, we do not yet know how a limited number of on-body calibrations on a set of subjects can be translated into a general calibration factor valid for the whole population (potentially taking into account body types). Currently, the PDE is expanded to other DL frequency bands using multi-band antennas combined with RF nodes tuned to different frequency bands, in order to be able to measure exposure in different RF frequency bands simultaneously using the same approach.

\section{Conclusions}

An on-body calibrated PDE was employed, for the first time, to evaluate micro-environmental personal exposure to mobile phone base stations GSM $900 \mathrm{MHz}$ downlink in Australia and Belgium. The study revealed that the personal exposure levels measured in Australian microenvironments were generally lower than those in the Belgian microenvironments. The personal exposures across urban microenvironments were higher than those in the rural and suburban microenvironments. Likewise, the exposure levels across the outdoor microenvironments were much higher than those across the indoor microenvironments. A majority of the second measurements in the same site provided highly varied exposures. Overall, the PDE and the ExpoM-RFs measurements demonstrated good correlation. The study confirmed that the personal exposure levels reported in our study were well below the general public reference levels.

\section{Acknowledgements}

This research was supported by the Centre for Population Health Research on Electromagnetic Energy (PRESEE), Department of Epidemiology and Preventive Medicine, School of Public Health and Preventive Medicine, Monash University. The centre is funded by a grant from the National Health and Medical Research Council, Australia.

The authors would like to thank: i) Matthias Van den Bossche and Leen Verloock for their technical support, ii) Mr Suman Bajracharya, Dr Fabricio Fiengo Perez, Dr David Goddard and Dr Diogenes Seraphim Ferreira for their kind help in carrying out field measurements employing car and bicycle. 


\section{REFERENCES}

ACMA communications report, 2014. Communications reports 2013-14. http://www.acma.gov.au/ /media/Research\%20and\%20Analysis/Publication/Comms \%20Report\%202013\%2014/PDF/Communications\%20report\%20201314_LOWRES\%20FOR\%20WEB\%20pdf.pdf. Accessed on 12.09.2015.

ACMA paper, 2015. Beyond 2020 - A spectrum management strategy to address the growth in mobile broadband capacity. Discussion paper. http://www.acma.gov.au/Industry/Spectrum/Spectrum-planning/About-spectrumplanning/acma-focuses-on-future-of-mobile-broadband-spectrum. Accessed on 12.09.2015.

Antenna Site Register, 2015. http://www.sites.bipt.be/index.php?language=EN. Accessed on 30.09.2015.

Bhatt, C.R., Redmayne, M., Abramson, M., Benke, G., 2015. Instruments to assess and measure personal and environmental radiofrequency-electromagnetic field exposures. Australas Phys. Eng. Sci. Med.. pp 1-14. DOI 10.1007/s13246-015-0412-z.

Bolte, J.F., van der Zande, G, Kamer, J., 2011. Calibration and uncertainties in personal exposure measurements of radiofrequency electromagnetic fields. Bioelectromagnetics 32, 652-663.

Bolte, J.F.B., Eikelboom, T., 2012. Personal radiofrequency electromagnetic field measurements in the Netherlands: Exposure level and variability for everyday activities, times of day and types of area. Environ Int. 48,133-142.

Dürrenberger, G., Fröhlich, J., Röösli, M., Mattsson, M.O., 2014. EMF monitoringconcepts, activities, gaps and options. Int J Environ Res Public Health 11, 9460-9479.

Frei, P., Mohler, E., Neubauer, G., Theis, G., Burgi, A., Frohlich, J., Braun-Fahrlander, C., Bolte, J., Egger, M., Röösli, M., 2009. Temporal and spatial variability of personal exposure to radio frequency electromagnetic fields. Environ Res. 109, 779-785.

Gajšek, P., Ravazzani, P., Wiart, J., Grellier, J., Samaras, T.,Thuróczy, G., 2015. Electromagnetic field exposure assessment in Europe radiofrequency fields ( $10 \mathrm{MHz}-$ $6 \mathrm{GHz}$ ). J Expo Sci Environ Epidemiol. 25, 37-44.

ICNIRP, 1998. The International Commission on Non-ionizing Radiation Protection. Guidelines for limiting exposure to time-varying electric, magnetic, and electromagnetic fields ( up to $300 \mathrm{GHz}$ ). Health Phys. 74 (4), 494-522.

Iskra, S., McKenzie, R.J., Cosic, I., 2011. Monte Carlo simulations of the electric field close to the body in realistic environments for application in personal radiofrequency dosimetry. Radiat Prot Dosimetry. 147, 517-527.

Henderson, S., Bangay, M., 2006. Survey of RF exposure levels from mobile telephone base stations in Australia. Bioelectromagnetics 27, 73-76.

Joseph, W., Frei, P., Roösli, M., Thuróczy, G., Gajsek, P., Trcek, T., Bolte, J., Vermeeren, G., Mohler, E., Juhász, P., Finta, V., Martens, L., 2010. Comparison of personal radio frequency electromagnetic field exposure in different urban areas across Europe. Environ Res. 110, 658-663.

Joseph, W., Verloock, L., 2010. Influence on mobile phone traffic on base station exposure of the general public. Health Phys. 99(5), 631-638.

Juhász, P., Bakos, J., Nagy, N., Jánossy, G, Finta, V,, Thuróczy, G., 2011. RF personal exposimetry on employees of elementary schools, kindergartens and day nurseries as a proxy for child exposures. Prog Biophys Mol Biol. 107, 449-455.

International Telecommunication Union, 2010. The evolution to $3 \mathrm{G}$ mobile-status report. Accessed on 27.02.2016. 
Kim, K., Kim, H-J., Song, D.J., Cho,Y.M., Choi, J.W., 2014. Risk perception and public concerns of electromagnetic waves from cellular phones in Korea. Bioelectromagnetics 35 (4), 235-244.

Mann, S., 2010. Assessing personal exposures to environmental radiofrequency electromagnetic fields. Comptes Rendus Physique. 11, 541-555.

Manassas, A., Boursianis, A., Samaras, T., Sahalos, J.N., 2012. Continuous electromagnetic radiation monitoring in the environment: analysis of the results in Greece. Radiat Prot Dosimetry. 151(3), 437-442.

Neubauer, G., Cecil, S., Giczi, W., Petric, B., Preiner, P., Fröhlich, J.,Röösli, M., 2010. The association between exposure determined by radiofrequency personal exposimeters and human exposure: a simulation study. Bioelectromagnetics 31, 535-545.

OpenSignal, 2015. http://opensignal.com/. Accessed on 17.08.2015.

Radiation Protection Standard, 2002. Maximum Exposure Levels to Radiofrequency Fields $-3 \mathrm{kHz}$ to $300 \mathrm{GHz}$. Radiation Protection Series Publication No. 3. the Australian Radiation Protection and Nuclear Safety Agency, pp 1-128.

Radio Frequency National Site Archive, 2015. http://www.rfnsa.com.au/nsa/index.cgi?type=logout Accessed on 17.08.2015.

Röösli, M., Frei, P., Bolte, J., Neubauer, G., Cardis, E., Feychting, M., Gajsek, P., Heinrich, S., Joseph, W., Mann, S., Martens, L., Mohler, E., Parslow, R.C., Poulsen, A.H., Radon, K., Schuz, J., Thuroczy, G., Viel, J.F.,Vrijheid, M., 2010. Conduct of a personal radiofrequency electromagnetic field measurement study: proposed study protocol. Environ Health. 9, 23, 1-14.

Rowley, J.T., Joyner, K.H., 2012. Comparative international analysis of radiofrequency exposure surveys of mobile communication radio base stations. J Expo Sci Environ Epidemiol. 22, 304-315.

Thielens, A., Agneessens, S., Verloock, L., Tanghe, E., Rogier, H., Martens, L., Joseph, W., 2015a. On-body calibration and processing for a combination of two radio-frequency personal exposimeters. Radiat Prot Dosimetry.163, 58-69.

Thielens, A., Agneessens, S., De Clercq, H., Lecoutere, J., Verloock, L., Tanghe, E., Aerts, S., Puers, R., Rogier, H., Martens, L., Joseph, W. 2015b. On-body Calibration and Measurements using a Personal, Distributed Exposimeter for Wireless Fidelity. Health Phys. 108(4), 407-418.

Thielens, A., De Clercq, H., Agneessens, S., Lecoutere, J., Verloock, L., Declercq, F., Vermeeren, G., Tanghe, E., Rogier, H.,Puers, R., 2013. Personal distributed exposimeter for radio frequency exposure assessment in real environments. Bioelectromagnetics 34, 563-567.

Thielens, A., Vanveerdeghem, P., Agneessens, S., Van Torre, P., Vermeeren, G., Rogier, H., Martens, L., Joseph, W., 2015c. Whole-Body Averaged Specific Absorption rate stimation using a Personal Distributed Exposimeter. IEEE AWPL 14, 1534-1537.

Tjong, L., Grzechnik, M., Karipidis, K., Tinker, R., 2015. Communicating with the public recent ARPANSA updates. Proc the $40^{\text {th }}$ Australasian Radiation Protection Society Conference, Canberra, Australia, 6-9 October 2015.

Urbinello, D., Joseph, W., Verloock, L., Martens, L., Röösli, M., 2014a. Temporal trends of radio-frequency electromagnetic field (RF-EMF) exposure in everyday environments across European cities. Environ Res. 134, 134-142.

Urbinello, D., Joseph, W., Huss, A., Verloock, L., Beekhuizen, J., Vermeulen, R., Martens, L.,Roosli, M., 2014b. Radio-frequency electromagnetic field (RF-EMF) exposure levels in different European outdoor urban environments in comparison with regulatory limits. Environ Int. 68, 49-54. 
Urbinello, D., Huss, A., Beekhuizen, J., Vermeulen, R., Röösli, M., 2014c. Use of portable exposure meters for comparing mobile phone base station radiation in different types of areas in the cities of Basel and Amsterdam. Sci Total Environ. 468-469:10281033.

van Deventer, E., van Rongen, E.,Saunders, R., 2011. WHO research agenda for radiofrequency fields. Bioelectromagnetics 32, 417-421.

Vermeeren, G., Markakis, I., Goeminne, F., Samaras, T., Martens, L.,Joseph, W., 2013. Spatial and temporal RF electromagnetic field exposure of children and adults in indoor micro environments in Belgium and Greece. Prog Biophys Mol Biol. 113, 254-263.

Vanveerdeghem, P., Vantorre, P., Thielens, A., Knockaert, J., Joseph, W., Rogier, H. 2015. Compact Personal Distributed Wearable Exposimeter. IEEE Sensors Journal 15(8), 4393-4401.

Wiedemann, P. M., Boerner, F. U., Repacholi, M. H., 2014. Do people understand IARC's $2 B$ categorization of RF fields from cell phones? Bioelectromagnetics 35, 373-378. 


\section{Appendix A}

Table 1: A summary of the microenvironments, their characteristics and the associated activities of the subject

\begin{tabular}{|c|c|c|c|}
\hline Microenvironments & Countries & $\begin{array}{l}\text { Study sites and } \\
\text { characteristics }\end{array}$ & Activities \\
\hline \multirow[t]{2}{*}{ Residential outdoor (urban) } & Australia $^{2}$ & $\begin{array}{l}\text { Windsor, Melbourne; } \\
\text { attached houses mostly up } \\
\text { to } 2 \text { storey, few }>3-6 \\
\text { storey buildings }\end{array}$ & $\begin{array}{l}\text { Walking through } \\
\text { streets }\end{array}$ \\
\hline & Belgium $^{1}$ & $\begin{array}{l}\text { Gent-Ledeberg; attached } \\
\text { houses mostly up to } 3 \\
\text { storey, busy streets, and a } \\
\text { church }\end{array}$ & \\
\hline Residential indoor (urban) & Australia $^{2}$ & $\begin{array}{l}\text { Prahran townhouse, ground } \\
\text { floor }\end{array}$ & $\begin{array}{l}\text { Walking inside the } \\
\text { different rooms of the } \\
\text { house }\end{array}$ \\
\hline \multirow[t]{2}{*}{ Office indoor (urban) } & Australia $^{2}$ & $\begin{array}{l}\text { Commercial Rd, } \\
\text { Melbourne ( } 5^{\text {th }} \text { floor); a 7- } \\
\text { storey university building, } \\
\text { multistorey hospital } \\
\text { buildings and academic } \\
\text { centres, a park and } \\
\text { residential area nearby }\end{array}$ & $\begin{array}{l}\text { Sitting on the chair at } \\
\text { the working desk, } \\
\text { walking around the } \\
\text { office rooms }\end{array}$ \\
\hline & Belgium $^{2}$ & $\begin{array}{l}\text { Gaston Crommenlaan, } \\
\left.\text { Gent ( } 2^{\text {nd }} \text { and } 3^{\text {rd }} \text { floor }\right) \text {; a } \\
\text { typical multistorey public } \\
\text { office building }\end{array}$ & \\
\hline \multirow[t]{2}{*}{ Park (urban) } & Australia $^{2}$ & $\begin{array}{l}\text { Fawkner Park, South } \\
\text { Yarra, Melbourne; a } \\
\text { typical public park with } \\
\text { many trees, roads } \\
\text { surrounding the park with } \\
\text { closely attached } \\
\text { buildings/houses on the } \\
\text { two sides of park, bus/tram } \\
\text { stations nearby }\end{array}$ & $\begin{array}{l}\text { Walking around the } \\
\text { park }\end{array}$ \\
\hline & Belgium $^{2}$ & $\begin{array}{l}\text { Koning Albertpark, Ghent; } \\
\text { a typical public park, roads } \\
\text { surrounding the park with } \\
\text { closely attached } \\
\text { buildings/houses on the } \\
\text { two sides of park, bus/tram } \\
\text { stations nearby }\end{array}$ & \\
\hline City centre & Australia $^{2}$ & $\begin{array}{l}\text { Federation Square, } \\
\text { Melbourne; an open city } \\
\text { area with bus/tram station, } \\
\text { central business district } \\
\text { with many tall buildings, } \\
\text { including few up to }>50 \\
\text { storeys, Yarra river nearby }\end{array}$ & $\begin{array}{l}\text { Walking around the } \\
\text { city square }\end{array}$ \\
\hline
\end{tabular}




\begin{tabular}{|c|c|c|c|}
\hline & Belgium $^{1}$ & $\begin{array}{l}\text { Korenmarkt, Gent; an open } \\
\text { city area with bus/tram } \\
\text { station, church and other } \\
\text { historical buildings nearby }\end{array}$ & \\
\hline \multirow[t]{2}{*}{ Library (urban) } & Australia $^{2}$ & $\begin{array}{l}\text { Prahran, Melbourne; a } \\
\text { public library with } 25-30 \\
\text { people inside, densely } \\
\text { packed area with attached } \\
\text { buildings/houses mostly up } \\
\text { to 3-4 storey }\end{array}$ & $\begin{array}{l}\text { Walking inside the } \\
\text { library, checking } \\
\text { books, reading } \\
\text { newspapers (standing) }\end{array}$ \\
\hline & Belgium $^{1}$ & $\begin{array}{l}\text { Zuid, Ghent; a public } \\
\text { library with two levels, bus } \\
\text { and tram station nearby, a } \\
\text { park on its one side and } \\
\text { city buildings around }\end{array}$ & \\
\hline \multirow[t]{2}{*}{ Shopping centre (urban) } & Australia $^{1}$ & $\begin{array}{l}\text { Bourke Street, Melbourne; } \\
\text { a 2-storey shopping mall }\end{array}$ & $\begin{array}{l}\text { Walking inside the } \\
\text { mall as a customer }\end{array}$ \\
\hline & Belgium $^{1}$ & $\begin{array}{l}\text { Zuid, Gent; 5-storey } \\
\text { shopping mall with an } \\
\text { open space in the centre of } \\
\text { the building }\end{array}$ & \\
\hline \multirow[t]{2}{*}{ Railway station (urban) } & Australia $^{2}$ & $\begin{array}{l}\text { Southern Cross Station, } \\
\text { Melbourne; the largest } \\
\text { train station in Victoria } \\
\text { with regional railway and } \\
\text { city metro networks ( } 2- \\
\text { storey), retail stores and } \\
\text { cafes }\end{array}$ & $\begin{array}{l}\text { Standing and walking } \\
\text { in the waiting hall of } \\
\text { the station }\end{array}$ \\
\hline & Belgium $^{1}$ & $\begin{array}{l}\text { Gent-Sint-Pieters railway } \\
\text { station; the main railway } \\
\text { station in Gent and one of } \\
\text { the busiest railway stations } \\
\text { in Belgium, retail stores } \\
\text { and cafes }\end{array}$ & \\
\hline \multirow[t]{2}{*}{ Tram station (urban) } & Australia $^{2}$ & $\begin{array}{l}\text { Domain Interchange, } \\
\text { Melbourne; a typical tram } \\
\text { station with } 15-20 \text { people } \\
\text { around, business and } \\
\text { public buildings nearby }\end{array}$ & $\begin{array}{l}\text { Standing and walking } \\
\text { around the tram } \\
\text { waiting points }\end{array}$ \\
\hline & Belgium $^{1}$ & $\begin{array}{l}\text { Zuid station, Gent; a } \\
\text { typical tram/bus station } \\
\text { with } 20-30 \text { people around, } \\
\text { buildings and shopping } \\
\text { centres nearby }\end{array}$ & \\
\hline \multirow[t]{2}{*}{ Bicycle (urban) } & Australia $^{2}$ & $\begin{array}{l}\text { Commercial road- } \\
\text { Birdwood Ave, Melbourne; } \\
\text { park and attached } \\
\text { houses/multistorey } \\
\text { buildings (up to } 10 \text { levels) } \\
\text { on the both sides of the } \\
\text { road, trees along the } \\
\text { roadside }\end{array}$ & $\begin{array}{l}\text { Riding a bicycle } \\
\text { around }\end{array}$ \\
\hline & Belgium $^{1}$ & $\begin{array}{l}\text { Gaston Crommenlaan and } \\
\text { Zuid, Gent; roads (with a } \\
\text { flyover), park and attached } \\
\text { houses and multistorey } \\
\text { buildings on the sides of } \\
\text { the roads and park }\end{array}$ & $\begin{array}{l}\text { Riding a bicycle } \\
\text { around }\end{array}$ \\
\hline
\end{tabular}




\begin{tabular}{|c|c|c|c|}
\hline Bus (urban) & Australia $^{2}$ & $\begin{array}{l}\text { Alfred hospital-Cardigan } \\
\text { street, Melbourne; the } \\
\text { public bus plied through } \\
\text { the area with mostly } 3-4 \\
\text { storey houses and a few big } \\
\text { buildings, on average } 10- \\
15 \text { people on board }\end{array}$ & $\begin{array}{l}\text { Standing and sitting on } \\
\text { a seat located in the } \\
\text { middle part of the bus }\end{array}$ \\
\hline & Belgium $^{2}$ & $\begin{array}{l}\text { Zuid-Merelbeke, and } \\
\text { Zuid-Fratersplein, } \\
\text { Gent; the public bus plied } \\
\text { through the area with } \\
\text { mostly } 3-4 \text { storey houses } \\
\text { and few big buildings, on } \\
\text { average } 20-25 \text { people on } \\
\text { board }\end{array}$ & \\
\hline \multirow[t]{2}{*}{ Car (urban) } & Australia $^{1}$ & $\begin{array}{l}\text { Eaglemont-Eltham, } \\
\text { Melbourne; streets with } \\
\text { normal urban/suburban } \\
\text { traffic and densely packed } \\
\text { area and detached houses } \\
\text { mostly up to 2-3 storey }\end{array}$ & $\begin{array}{l}\text { Sitting on the front } \\
\text { seat of the car }\end{array}$ \\
\hline & Belgium $^{2}$ & $\begin{array}{l}\text { Gaston Crommenlaan - } \\
\text { Dampoort, and Gaston } \\
\text { Crommenlaan- Sint-Pieters } \\
\text { station; streets with busy } \\
\text { traffic and densely packed } \\
\text { areas with some tall public } \\
\text { and commercial buildings }\end{array}$ & \\
\hline \multirow[t]{2}{*}{ Tram (urban) } & Australia $^{2}$ & $\begin{array}{l}\text { The Alfred hospital- } \\
\text { Collins street, Melbourne; } \\
\text { on average } 20-25 \text { people } \\
\text { on board }\end{array}$ & $\begin{array}{l}\text { Standing and sitting on } \\
\text { a seat }\end{array}$ \\
\hline & Belgium $^{1}$ & $\begin{array}{l}\text { Jacques Eggermontstraat- } \\
\text { Zwijnaarde, Gent; on } \\
\text { average } 15-20 \text { people on } \\
\text { board }\end{array}$ & \\
\hline \multirow[t]{2}{*}{ Train } & Australia $^{2}$ & $\begin{array}{l}\text { Flinders Street- } \\
\text { Elsternwick, Melbourne } \\
\text { (urban), on average 20-30 } \\
\text { people on board }\end{array}$ & $\begin{array}{l}\text { Standing, sitting on a } \\
\text { seat }\end{array}$ \\
\hline & Belgium $^{1}$ & $\begin{array}{l}\text { Gent-Antwerp (urban and } \\
\text { suburban), on average } 20- \\
30 \text { people on board }\end{array}$ & $\begin{array}{l}\text { Standing, sitting on a } \\
\text { seat }\end{array}$ \\
\hline Bicycle (rural/suburban) & Belgium $^{1}$ & $\begin{array}{l}\text { Boeretang, Mol; a few } \\
\text { scattered houses up to } 3 \\
\text { storey, a pine tree forest } \\
\text { and open agricultural } \\
\text { fields, } 3 \text { kilometres from } \\
\text { a small town (Mol) }\end{array}$ & $\begin{array}{l}\text { Riding a bicycle } \\
\text { around }\end{array}$ \\
\hline Car (rural/suburban) & Belgium $^{1}$ & $\begin{array}{l}\text { Boeretang-Mol; car ride } \\
\text { via areas with agricultural } \\
\text { fields, forests, and } \\
\text { residential sites }\end{array}$ & $\begin{array}{l}\text { Sitting on the front } \\
\text { seat of the car }\end{array}$ \\
\hline $\begin{array}{l}\text { Residential indoor } \\
\text { (rural/suburban) }\end{array}$ & Belgium $^{2}$ & $\begin{array}{l}\text { Boeretang, Mol; a 3-storey } \\
\text { residential quarter, a pine } \\
\text { tree forest, agricultural } \\
\text { fields and a canal around }\end{array}$ & $\begin{array}{l}\text { Walking and sitting in } \\
\text { the common room, } \\
\text { kitchen, etc. }\end{array}$ \\
\hline $\begin{array}{l}\text { Residential outdoor (rural } \\
\text { /suburban) }\end{array}$ & Australia $^{2}$ & $\begin{array}{l}\text { Tarrawarra, Victoria; few } \\
\text { scattered houses, } \\
\text { agricultural fields }\end{array}$ & $\begin{array}{l}\text { Walking around the } \\
\text { area }\end{array}$ \\
\hline
\end{tabular}




\begin{tabular}{|c|c|c|c|}
\hline & Belgium $^{2}$ & $\begin{array}{l}\text { Boeretang, Mol; a few } \\
\text { scattered houses, pine tree } \\
\text { forests, a canal and } \\
\text { agricultural fields around }\end{array}$ & \\
\hline $\begin{array}{l}\text { Subway station/ride } \\
\text { (urban) }\end{array}$ & Australia $^{1}$ & $\begin{array}{l}\text { Parliament-Flagstaff, } \\
\text { Melbourne; a typical } \\
\text { subway station with } 20-30 \\
\text { people around and } 20-25 \\
\text { people on the train carriage }\end{array}$ & $\begin{array}{l}\text { Standing both at the } \\
\text { station and on the } \\
\text { metro }\end{array}$ \\
\hline Mountain/forest (rural) & Australia $^{1}$ & $\begin{array}{l}\text { Cathedral Range State } \\
\text { Park, Taggerty, Victoria; } \\
\text { forested hills, one person } \\
\text { around }\end{array}$ & $\begin{array}{l}\text { Walking along trails in } \\
\text { forest area }\end{array}$ \\
\hline
\end{tabular}

$1=$ single measurement, 2 = repeated (second) measurement

\section{Appendix B}

\section{On-body Calibration Procedure}

In step one, the $E_{\text {inc }}$ was measured without the subject present in the fully-anechoic chamber. The measurements of $E_{\text {inc }}$ were carried out along the axis of rotation of the platform using a NBM-550 broadband field meter (Narda, Hauppauge, NY, USA). The $E_{\text {inc }}$ values were then averaged over the height of the subject (INCIRP, 1998). This procedure was repeated for two orthogonal polarizations of the $T_{X}$ : parallel to the axis of rotation (V-polarization) and parallel to the floor of the chamber $(\mathrm{H}-$ polarization).

In step two, the subject equipped with the PDE stood on the rotational platform in the far field of the $T_{X}$. Three on-body antennas (Thielens et al., 2013; Vanveerdeghem et al., 2015) were placed on the locations shown in Fig. 1 a \& b. The used antennas are linearly polarized planar inverted F-antennas (Thielens et al., 2013; Vanveerdeghem et al., 2015). The two antennas placed on the front of the torso have orthogonal polarizations, which enables the device to measure two orthogonal incident far-field polarizations. The antennas are connected, using a shielded SubMiniature version A cable, with RF nodes that contain a surface acoustic wave filter tuned to the $900 \mathrm{MHz}$ downlink band (925-960 MHz). The SAW filter provides an out-of-band isolation of more than $23 \mathrm{~dB}$ (Vanveerdeghem et al. 2015). The cables shown in Fig. 1 are used to connect the RF nodes with a battery which is worn on the hips of the subject and do not influence the RF performance of the PDE. The cables and the battery are included in the on-body calibration. The subject was rotated over $360^{\circ}$ in azimuthal direction from a constant electric field $\left(E_{\text {inc }}\right)$, which was V-polarized during the first rotation and then H-polarized. This rotation represented the unknown orientation of the subject in an exposure situation (Thielens et al., 2013). During the rotation the antennas recorded received powers $\left(P_{r}\right)$ on the body. These received powers depend on the rotational angle, due to shadowing of the body (Thielens et al., 2015b, 2013; Vanveerdeghem et al., 2015), and the polarization of the $T_{X}$.

The received powers $\left(P_{r}\right)$ were related to the incident electric field strength $\left(E_{\text {inc }}\right)$ through the effective antenna aperture $(A A)$ :

$$
A A=\frac{377 \times P_{r}}{E_{\text {inc }}{ }^{2}}
$$

Since $P_{r}$ depends on the angle of incidence, the $A A$ will have a distribution. In determining its distribution, we assumed both polarizations to be equally likely to occur. The distribution of $A A$ was 
characterized by its median value $\left[p_{50}(A A)\right]$ and $50 \%$ prediction interval $P I_{50}$ (with $p_{25}(A A)$ and $p_{75}(A A)$, the $25^{\text {th }}$ and $75^{\text {th }}$ percentile of the distribution of $\left.A A\right)$ :

$$
P I_{50}=\frac{p_{75}(A A)}{p_{25}(A A)}
$$

A perfect exposimeter, i.e. an antenna with a constant $A A$, will have a $P I_{50}=1$, so a value close to one is desirable.

During measurements, the incident field strengths can be estimated from the measured received powers $\left(P_{r}\right)$ using this antenna aperture. In this study, we estimated the incident field strength $\left(\widehat{E}_{\text {inc }}\right)$, using the median $A A\left[p_{50}(A A)\right]$ :

$$
\hat{E}_{i n c}=\sqrt{\frac{377 \times P_{r}}{p_{50}(A A)}}
$$

In step three, two ExpoM-RFs were employed in the on-body calibration process to determine the relationship between the incident electric field strengths $\left(E_{\text {inc }}\right)$ and the electric field strengths on the body $\left(E_{b o d y}\right)$. These devices are meant to measure $E_{\text {inc }}$, but since they were worn on the body during measurements, they registered $E_{\text {body }}$ instead (Bolte et al., 2011, Thielens et al., 2015a). The human subject equipped with the ExpoM-RFs (as shown in Figure 1c) stood on the rotational platform in the far field of the $T_{X}$. Two ExpoM-RFs were placed to the body (Thielens et al., 2013, Vanveerdeghem et al., 2015) on the locations of each hip. The subject was rotated over $360^{\circ}$ in azimuthal direction, while being exposed to a constant electric field $\left(E_{\text {inc }}\right)$, which is first V-polarized and then H-polarized. This rotation represented the unknown orientation of the subject in an exposure situation (Thielens et al., 2013). During the rotation, the ExpoM-RFs recorded the electric fields on the body $\left(E_{b o d y}\right)$. These onbody fields and received powers depend on the rotational angle, due to shadowing of the body (Thielens et al., 2013, 2015b, Vanveerdeghem et al., 2015), and the polarization of the $T_{X}$. The $E_{b o d y}$ values were not the same as the incident values $\left(E_{\text {inc }}\right)$ (Thielens et al., 2015a), therefore, the response $(R)$ of the ExpoM-RFs was evaluated as:

$$
R=\frac{E_{\text {body }}}{E_{\text {inc }}}
$$

$R>1$ and $<1$ indicated an overestimation or an underestimation respectively. $R$ is not a constant and will have a certain distribution (Thielens et al., 2015a) for each of the two measured orientations of the $T_{X}$. In the processing of the results, we made no a-priori assumptions on the incident polarization of the realistic fields and thus assumed each polarization to be equally likely. Therefore, all measured $R$ values were combined in one distribution characterized by its median value $(\mathrm{p} 50(R))$ and $50 \%$ prediction interval $\left(P I_{50}\right)$ :

$$
P I_{50}=\frac{p_{75}(R)}{p_{25}(R)}
$$

with $p 75(R)$ and $p 25(R)$ indicating the $75^{\text {th }}$ and $25^{\text {th }}$ percentiles of $R$, respectively. During measurements, the incident field strengths can be estimated from the measured electric field strengths $\left(E_{\text {meas }}\right)$ using this response. We estimated the incident field strength $\left(\widehat{\mathrm{E}}_{\mathrm{inc}}\right)$, using the median $(p 50(R))$ : 


$$
\widehat{E}_{\text {inc }}=\frac{E_{\text {meas }}}{p_{50}(R)}
$$

with $E_{\text {meas }}$ the geometric averaged measured electric field strength.

The used calibration procedure is valid for far-field exposure, but might not be suitable for sources close to the body such as mobile phones or personal devices, which might cause a large variation of the electric field strength on the body. The calibration procedure can be used in this study, where far-field, downlink exposure around $900 \mathrm{MHz}$ is studied. 